\title{
The role of trait anxiety in associative learning during and after an aversive event
}

\author{
Arne Ilse, ${ }^{1}$ Virginia Prameswari, ${ }^{1}$ Evelyn Kahl, ${ }^{2}$ and Markus Fendt ${ }^{2,3}$ \\ ${ }^{1}$ Integrative Neuroscience Program; ${ }^{2}$ Institute for Pharmacology and Toxicology; ${ }^{3}$ Center for Behavioral Brain Sciences, Otto-von- \\ Guericke University Magdeburg, 39120 Magdeburg, Germany
}

\begin{abstract}
Trait anxiety is considered to be a risk factor for anxiety disorders. The aim of the present study was to investigate how trait anxiety affects associative learning during and after an aversive event in laboratory rats. For this, rats were first submitted to a light-dark box test, followed by relief, safety, and fear learning. Our data demonstrate that all types of learning were affected by trait anxiety, both on a group and on an individual level. Whereas high levels of anxiety impaired relief and safety learning, fear learning was more pronounced. These findings help to show how trait anxiety might be involved in the etiology of anxiety disorders and pathological sensation- and risk-seeking.
\end{abstract}

During Pavlovian fear conditioning, humans and animals learn to associate a formerly neutral stimulus with an aversive event (LeDoux 2012). After successfully forming this association, the then conditioned stimulus (CS) induces conditioned fear which can be measured, for example, by potentiated startle magnitudes or by the expression of freezing behavior in the presence of the CS (Fendt and Fanselow 1999). However, humans and animals cannot only associate a stimulus with the presence of an aversive event but also with its cessation or absence. Associating the cessation of an aversive event with an environmental stimulus is called relief learning (Gerber et al. 2014). Relief from an aversive event is rewarding (Leknes et al. 2011) and a relief CS induces appetitive-like behavioral changes in humans and rodents (Gerber et al. 2014). Different from relief learning is safety learning. In safety learning, not the cessation but the absence of the aversive event is associated with an environmental stimulus (Pollak et al. 2008). Later, a safety CS inhibits fear and/or induces appetitive-like behavioral changes. Fear conditioning is a potent paradigm to investigate the neural circuitry underlying fear learning (Maren and Quirk 2004) and to test drugs for their potential to be used to treat anxiety disorders (Cryan and Sweeney 2011). Much of this research was motivated by studies showing that fear learning and its extinction is affected in anxiety disorder patients (for review, see Lissek et al. 2005). However, several findings indicate that impaired safety learning may also contribute to the etiology of anxiety disorders (Lohr et al. 2007; Pollak et al. 2008; Lissek et al. 2009, 2010; Jovanovic et al. 2012). Interestingly, enhanced fear learning and impaired safety learning cannot only be observed in anxiety disorder patients but also in high trait anxiety individuals (Haddad et al. 2012; Gazendam et al. 2013; Andreatta and Pauli 2017).

Trait anxiety is considered to be a risk factor for anxiety disorders (Chambers et al. 2004). Therefore, improving our knowledge on how trait anxiety influences fear, safety, and relief learning may help to better understand the etiology of anxiety disorders. Although there are several well-established rodent paradigms for trait anxiety (Cryan and Sweeney 2011), the role of trait anxiety in fear, safety, and relief learning in rodents is poorly investigated. To the best of our knowledge, only rats and mice selectively bred for high anxiety were tested in fear conditioning so far (Muigg et al. 2008; Sartori et al. 2011).

Corresponding author: markus.fendt@med.ovgu.de Article is online at http://www.learnmem.org/cgi/doi/10.1101//m.048595.118.
The aim of our study was to investigate the role of trait anxiety on fear, safety, and relief learning in rats. To test trait anxiety, we used the light-dark box test (Bourin and Hascoët 2003). We then submitted the animals to relief, safety, and fear learning. Retention of learned relief and learned safety was measured by the modulation of startle response (Andreatta et al. 2012; Mohammadi et al. 2014), whereas retention of learned contextual and cued fear was measured by freezing (Schwienbacher et al. 2006). To analyze the impact of trait anxiety on these different types of learning, we performed two different analyses, one based on grouping animals with similar trait anxiety, the other one based on individual data.

For our experiments, 55 two-month-old male Wistar rats (in-house colony) were used. They were housed in groups of 3-6 animals under a 12-h light-dark cycle with freely available food and tap water. All experiments were carried out during the light phase, were performed in accordance with international ethical guidelines for the use of animals in experiments (2010/63/EU), and approved by the local authorities (Landesverwaltungsamt Sachsen-Anhalt, Az.42505-2-1172 UniMD).

The behavioral experiments started with the light-dark box test. The boxes $(49.5 \times 49.5 \times 41.5 \mathrm{~cm})$ consisted of a dark compartment (below 1 lux) and a light compartment (approximately 230 lux). The compartments were of identical size and separated by a wall with a $8 \times 6 \mathrm{~cm}$ opening. Movement of the rats was detected by a frame with infrared sensors (distance: $14 \mathrm{~mm}$; TSE Systems). To measure anxiety levels, the rats were put into the middle of the dark compartment and allowed to explore both compartments for $10 \mathrm{~min}$. As a behavioral readout for trait anxiety, we used the percent time spent in the light compartment.

After a break of 2-3 d, the rats were submitted to one of the two learning protocols described below, that is, either relief conditioning $(n=28)$ or safety conditioning $(n=27)$. Two to three days later, half of the animals were submitted to fear conditioning $(n=28)$.

Relief learning (cf. Andreatta et al. 2012) was performed in a startle system (SR-LAB, San Diego Instruments) with eight identical chambers equipped with acrylic cylinders (diameter: $9 \mathrm{~cm}$, length: $16 \mathrm{~cm}$ ) with a floor consisting of stainless steel bars and a

(C) 2019 Ilse et al. This article is distributed exclusively by Cold Spring Harbor Laboratory Press for the first 12 months after the full-issue publication date (see http://learnmem.cshlp.org/site/misc/terms.xhtml). After 12 months, it is available under a Creative Commons License (Attribution-NonCommercial 4.0 International), as described at http://creativecommons.org/licenses/by-nc/4.0/. 
piezoelectric transducer underneath. This transducer detected and measured the animals' movement, that is, the startle response. On the first day, the animals were habituated to the startle system and the startle stimuli. For this, the rats were placed into the cylinders and after a 5 min acclimation period, 10 startle stimuli (white noise, duration: $40 \mathrm{msec}$, intensity: $96 \mathrm{~dB}$ SPL) were presented with an interstimulus interval of $30 \mathrm{sec}$. One day later, relief conditioning was performed. After 5 min acclimation time, 15 pairings of a footshock (unconditioned stimulus [US]: delivered via the steel bars, duration: $0.5 \mathrm{sec}$, intensity: $0.4 \mathrm{~mA}$ ) and a light stimulus (CS: duration: $5 \mathrm{sec}$, intensity: $1000 \mathrm{lux}$ ) were presented. These two stimuli were backward paired, that is, the light stimulus was presented $3 \mathrm{sec}$ after the shock onset. The mean intertrial interval was $2 \mathrm{~min}$ (range: 1.5-2.5 $\mathrm{min}$ ). On the third day, a retention test was performed. After 5 min acclimation, 10 startle stimuli were presented with an intertrial interval of $30 \mathrm{sec}$. Then, 20 further startle stimuli were presented, 10 of them without the CS (startle alone trials) and 10 of them upon presentation of the CS (CS-startle trials). The order of the trials with and without CS was pseudo-randomized.

The procedure for safety learning was identical to the one for relief learning despite a different timing of the US and the CS during the conditioning procedure (cf. Mohammadi et al. 2014). For safety conditioning, in order to explicitly unpair the CS with the US, the US was never presented less than $12 \mathrm{sec}$ before or after the CS, otherwise presented with a random interstimulus interval. This resulted in US-free periods of 42-130 sec (mean: $86.5 \mathrm{sec}$ ).

For fear learning (cf. Khalil and Fendt 2017), a fear conditioning system with four identical chambers was used (TSE Systems). Movements of the rats were detected by a frame with infrared sensors (distance: $14 \mathrm{~mm}$ ). Freezing was defined as no movement detection via the sensors for more than $1 \mathrm{sec}$. For the conditioning procedure, transparent boxes $(46 \times 46 \times 32 \mathrm{~cm})$ with floors consisting of stainless steel grids were used. Animals were put into these boxes and after an acclimation time of $2 \mathrm{~min}$, they received five pairings of tone CS (duration: $30 \mathrm{sec}$, frequency: $10 \mathrm{kHz}$, intensity: $80 \mathrm{~dB}$ SPL) with co-terminating footshocks (US: duration: $1 \mathrm{sec}$, intensity: $0.8 \mathrm{~mA}$ ) administered via the floor grid. On the next day, retention tests for conditioned contextual and cued fear, respectively, were performed. To test contextual fear, the rats were placed in the boxes which were used for fear conditioning for $5 \mathrm{~min}$ without any stimulus presentation and behavior was recorded. Three hours later, cued fear was measured in novel boxes (black walls, flat floor). In this novel context, the CS was presented 10 times with an interstimulus interval of $1 \mathrm{~min}$.

For descriptive and statistical analysis, we used Prism 6.0 (GraphPad Software Inc.). To investigate the effects of trait anxiety on the different types of event learning, two different analyses were performed for each event learning protocol. For the first analysis, animals were grouped based on their levels of anxiety (\% time spent in the light compartment) in the light-dark box. The third of rats with the lowest values built the group "high anxiety" (range: 0\%$26.0 \%$ ), the third with the highest values built the group "low anxiety" (range: $42.3 \%-68.6 \%$ ), and the remaining built the group "middle anxiety" (range: $28.5 \%-42.2 \%$ ). After checking the group data for normal distribution (D'Agostino-Pearson omnibus distribution test), the different types of event learning were compared using analysis of variance (ANOVA) or Kruskal-Wallis test. In the second analysis, a linear regression analysis was used to check whether the individual behavior in the light-dark box (i.e., percentage time spent in the light compartment) was correlated with the learning scores in the different event learning protocols.

In Figure $1 \mathrm{~A}$, the startle data from the retention test for conditioned relief are depicted. An ANOVA with trial type (startle alone vs. CS-startle) as within-subject factor and group (high, middle, and low anxiety) as between-subject factor was performed. There was no main effect of group $\left(F_{(2,25)}=0.48, P=0.63\right)$ indicating that anxiety did not generally affect startle magnitude. However, the relief CS had an significant main effect on the startle magnitude $\left(F_{(2,25)}=19.69, P<0.0001\right)$ and there was a significant interaction between trial type and group $\left(F_{(2,25)}=3.35, P=0.04\right)$. Post-hoc Sidak's multiple comparisons showed that the relief CS did not affect startle magnitude in the highest anxiety group $\left(t_{9}=0.50, P=\right.$ 0.94 ) but significantly decreased startle magnitude in the middle and low anxiety groups (middle: $t_{10}=2.97, P=0.02$; low: $t_{9}=4.24$, $P=0.0008)$. This was confirmed by an analysis of the difference scores (Kruskal-Wallis test: $H=8.78, P=0.01$ ) showing significant differences between the group with high anxiety scores and the group with low anxiety scores $(P=0.006)$. Regression analysis of the individual data (Fig. 1B) further revealed that light-dark box behavior was significantly correlated with the percent startle attenuation by the relief CS $\left(r^{2}=0.25 ; P=0.006\right)$.

Animals of the three different anxiety groups did not differ in the retention test on conditioned safety (Fig. 1C). There was a significant startle attenuation by the safety CS $\left(F_{(1,24)}=8.07, P=\right.$ $0.009)$ but neither an effect of group $\left(F_{(2,24)}=2.10, P=0.14\right)$ nor an interaction between group and trial type $\left(F_{(2,24)}=0.08, P=\right.$ $0.92)$. This is supported by the analysis of the absolute or percent difference scores $(H s<1.70, P s>0.42)$. However, the regression analysis of the individual data (Fig. 1D) showed that light-dark box behavior was significantly correlated with startle attenuation by the safety CS $\left(r^{2}=0.26, P=0.008\right)$.

Figure $1 \mathrm{E}$ shows the mean percent freezing during exposure to the fear conditioning boxes, before and after fear conditioning. Before conditioning, the context only induced minimal freezing in the high anxiety group. However, after fear conditioning, contextinduced freezing significantly differed between groups (KruskalWallis test: $H=6.35, P=0.04$ ). A post-hoc Dunn's test revealed a significant difference between the groups with high and low anxiety scores $(P=0.03)$, with low anxiety rats expressing less contextual freezing than high anxiety rats. In addition, the regression analysis showed that light-dark box behavior was significantly correlated with contextual freezing (Fig. $1 \mathrm{~F} ; r^{2}=0.15 ; P=0.04$ ).

These effects were more pronounced in the retention test on cued fear (Fig. 1G). The novel context induced some freezing in the groups with high and middle anxiety scores only. CS-induced freezing was significantly different in the three groups $\left(F_{(2,25)}=\right.$ 10.33, $P=0.0005)$. Post-hoc Dunnett's comparison showed that the groups with middle and low anxiety scores had significantly lower CS-induced freezing than the high anxiety rats (high vs. middle: $t=2.65, P=0.03$; high vs. low: $t=4.53, P=0.0003$ ). This is supported by the regression analysis showing a significant correlation between light-dark box behavior and CS-induced freezing (Fig. $1 \mathrm{H}$; $\left.r^{2}=0.41 ; P=0.0003\right)$.

Taken together, our data demonstrate that trait anxiety scores measured in rats (during the light-dark box test) are associated with their performance in retention tests on conditioned relief, safety, contextual, and cued fear. We used two different types of analyses, one based on grouping animals with similar levels of trait anxiety and the other one based on individual data. Regarding conditioned relief and fear, both analyses support each other, that is, the less anxious the animal, the more conditioned relief and the less conditioned cued and contextual fear was expressed. Grouping in the safety conditioned rats led to no significant difference, most probably due to the high variability within the groups. Nevertheless, regression analysis showed that less anxious rats perform better upon safety memory recall.

Our data are in line with findings from human studies showing that high trait anxiety is associated with impaired discrimination of fear, safety, and relief signals (Haddad et al. 2012; Gazendam et al. 2013; Andreatta and Pauli 2017). In contrast to the human studies, we did not test our animals for the ability to 

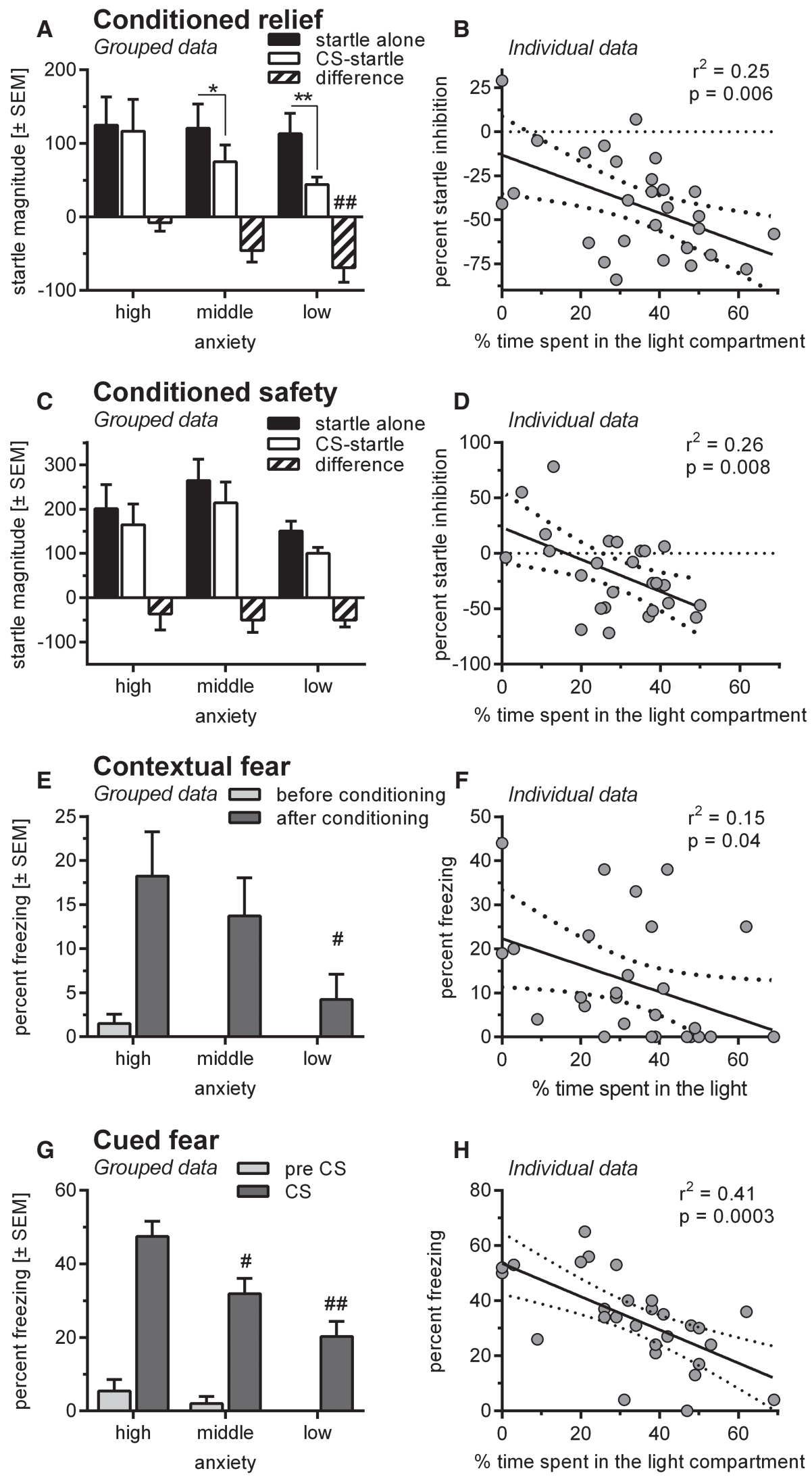

Figure 1. Impact of trait anxiety on associative learning during and after aversive events. For the bar diagrams, animals were grouped in thirds based on their anxiety-like behavior in the light-dark box test. In the XY diagram, data of individual animals are shown. Lower percentage time spent in the light compartment of the light-dark box indicates higher trait anxiety. The lower the anxiety scores, the more pronounced was relief learning, both on a group level $(A)$ and an individual level $(B)$. (C) Lower anxiety scores were also associated with better safety learning but only when analyzed on an individual level $(D)$. In contrast, lower anxiety scores lead to weaker fear learning of contextual $(E, F)$ and cued stimuli $(G, H)$, analyzed on a group level $(E, G)$ as well as on an individual level $(F, H) .\left(^{* *}\right) P<0.01,\left({ }^{*}\right) P<0.05$, post-hoc comparisons after significant ANOVA depicting the effects of the CS on startle magnitude. (\#\#) $P<0.01$, (\#) $P<$ 0.05 , post-hoc comparison with the respective value from the high anxiety group. Values in the XY diagrams indicate the results of a regression analysis. 
discriminate between signals with different meanings (neutral vs. fear vs. safety vs. relief) but rather for the strength of the different learning processes. Since the respective tests were separated, the present data demonstrate that all three learning processes are independently affected by trait anxiety. However, in this context, it should be noted that our animals were submitted to relief or safety learning before fear learning. This prior experience may have facilitated the effects of trait anxiety on fear learning (cf. Cordero et al. 2003).

Literature shows that subjects with high levels of anxiety do not only express exaggerated fear learning but also increased fear generalization (Dunsmoor et al. 2011). This increased fear generalization, together with impaired learning of stimuli associated with cessation or absence of aversive events (relief and safety), may be responsible for the poor discrimination abilities observed in high trait anxiety subjects. Unfortunately, low trait anxiety subjects have not been well investigated to the present day. Based on the present data, we predict that the low trait anxiety subjects are able to learn safety and relief signals well but have problems differentiating such cues from danger-associated signals. This might contribute to increased or even pathological risk- or sensationseeking behavior (but see Howlett and Paulus 2017).

To conclude, our study demonstrates that trait anxiety is correlated with associative learning during aversive events, with more anxious rats displaying stronger fear learning and weaker safety or relief learning. Thereby, trait anxiety could support overgeneralization of learned stimuli, negative interpretation of ambiguous stimuli, and misidentification of novel stimuli could be supported. Ultimately, these factors then may contribute to the etiology of anxiety disorders and disorders with pathological risk-/ sensation-seeking.

\section{Acknowledgments}

The authors are grateful to Judith Kreutzmann for helpful comments to the manuscript and language editing. This study was supported by the German Science Foundation (SFB779/B13).

\section{References}

Andreatta M, Pauli P. 2017. Learning mechanisms underlying threat absence and threat relief: influences of trait anxiety. Neurobiol Learn Mem 145: 105-113. doi:10.1016/j.nlm.2017.09.005.

Andreatta M, Fendt M, Mühlberger A, Wieser MJ, Imobersteg S, Yarali A, Gerber B, Pauli P. 2012. Onset and offset of aversive events establish distinct memories requiring fear- and reward networks. Learn Mem 19: 518-526. doi:10.1101/lm.026864.112.

Bourin M, Hascoët M. 2003. The mouse light/dark box test. Eur J Pharmacol 463: 55-65. doi:10.1016/S0014-2999(03)01274-3.

Chambers JA, Power KG, Durham RC. 2004. The relationship between trait vulnerability and anxiety and depressive diagnoses at long-term follow-up of generalized anxiety disorder. J Anxiety Disord 18: 587-607. doi:10.1016/j.janxdis.2003.09.001.

Cordero MI, Venero C, Kruyt ND, Sandi C. 2003. Prior exposure to a single stress session facilitates subsequent contextual fear conditioning in rats: evidence for a role of corticosterone. Horm Behav 44: 338-345. doi:10.1016/S0018-506X(03)00160-0.

Cryan JF, Sweeney FF. 2011. The age of anxiety: role of animal models of anxiolytic action in drug discovery. Br J Pharmacol 164: 1129-1161. doi:10.1111/j.1476-5381.2011.01362.x.
Dunsmoor JE, Prince SE, Murty VP, Kragel PA, LaBar KS. 2011

Neurobehavioral mechanisms of human fear generalization. Neuroimage 55: 1878-1888. doi:10.1016/j.neuroimage.2011.01.041.

Fendt M, Fanselow MS. 1999. The neuroanatomical and neurochemical basis of conditioned fear. Neurosci Biobehav Rev 23: 743-760. doi:10.1016/S0149-7634(99)00016-0.

Gazendam FJ, Kamphuis JH, Kindt M. 2013. Deficient safety learning characterizes high trait anxious individuals. Biol Psychol 92: 342-352. doi:10.1016/j.biopsycho.2012.11.006.

Gerber B, Yarali A, Diegelmann S, Wotjak CT, Pauli P, Fendt M. 2014. Pain-relief learning in flies, rats, and man: basic research and applied perspectives. Learn Mem 21: 232-252. doi:10.1101/lm.032995.113.

Haddad ADM, Pritchett D, Lissek S, Lau JYF. 2012. Trait anxiety and fear responses to safety cues: stimulus generalization or sensitization? J Psychopathol Behav Assess 34: 323-331. doi:10.1007/ s10862-012-9284-7.

Howlett JR, Paulus MP. 2017. Individual differences in subjective utility and risk preferences: the influence of hedonic capacity and trait anxiety. Front Psychiatry 8: 88. doi:10.3389/fpsyt.2017.00088.

Jovanovic T, Kazama A, Bachevalier J, Davis M. 2012. Impaired safety signal learning may be a biomarker of PTSD. Neuropharmacology 62: 695-704. doi:10.1016/j.neuropharm.2011.02.023.

Khalil R, Fendt M. 2017. Increased anxiety but normal fear and safety learning in orexin-deficient mice. Behav Brain Res 320: 210-218. doi:10.1016/j.bbr.2016.12.007.

LeDoux JE. 2012. Rethinking the emotional brain. Neuron 73: 653-676. doi:10.1016/j.neuron.2012.02.004.

Leknes S, Lee M, Berna C, Andersson J, Tracey I. 2011. Relief as a reward: hedonic and neural responses to safety from pain. PLoS One 6: e17870. doi:10.1371/journal.pone.0017870.

Lissek S, Powers AS, McClure EB, Phelps EA, Woldehawariat G, Grillon C, Pine DS. 2005. Classical fear conditioning in the anxiety disorders: a meta-analysis. Behav Res Ther 43: 1391-1424. doi:10.1016/j. brat.2004.10.007.

Lissek S, Rabin SJ, McDowell DJ, Dvir S, Bradford DE, Geraci M, Pine DS, Grillon C. 2009. Impaired discriminative fear-conditioning resulting from elevated fear responding to learned safety cues among individuals with panic disorder. Behav Res Ther 47: 111-118. doi:10.1016/j. brat.2008.10.017.

Lissek S, Rabin S, Heller RE, Lukenbaugh D, Geraci M, Pine DS, Grillon C. 2010. Overgeneralization of conditioned fear as a pathogenic marker of panic disorder. Am J Psychiatry 167: 47-55. doi:10.1176/appi. ajp.2009.09030410.

Lohr JM, Olatunji BO, Sawchuk CN. 2007. A functional analysis of danger and safety signals in anxiety disorders. Clin Psychol Rev 27: 114-126. doi:10.1016/j.cpr.2006.07.005.

Maren S, Quirk GJ. 2004. Neuronal signalling of fear memory. Nat Rev Neurosci 5: 844-852. doi:10.1038/nrn1535.

Mohammadi M, Bergado Acosta JR, Fendt M. 2014. Relief learning is distinguished from safety learning by the requirement of the nucleus accumbens. Behav Brain Res 272: 40-45. doi:10.1016/j.bbr.2014.06.053.

Muigg P, Hetzenauer A, Hauer G, Hauschild M, Gaburro S, Frank E, Landgraf R, Singewald N. 2008. Impaired extinction of learned fear in rats selectively bred for high anxiety - evidence of altered neuronal processing in prefrontal-amygdala pathways. Eur J Neurosci 28: 2299_ 2309. doi:10.1111/j.1460-9568.2008.06511.x.

Pollak DD, Monje FJ, Zuckerman L, Denny CA, Drew MR, Kandel ER. 2008. An animal model of a behavioral intervention for depression. Neuron 60: 149-161. doi:10.1016/j.neuron.2008.07.041.

Sartori SB, Hauschild M, Bunck M, Gaburro S, Landgraf R, Singewald N. 2011. Enhanced fear expression in a psychopathological mouse model of trait anxiety: pharmacological interventions. PLoS One 6: e16849. doi:10.1371/journal.pone.0016849.

Schwienbacher I, Schnitzler HU, Westbrook RF, Richardson R, Fendt M. 2006. Carbachol injections into the nucleus accumbens disrupts acquisition and expression of fear-potentiated startle and freezing in rats. Neuroscience 140: 769-778. doi:10.1016/j. neuroscience.2006.02.052.

Received October 5, 2018; accepted in revised form December 17, 2018. 


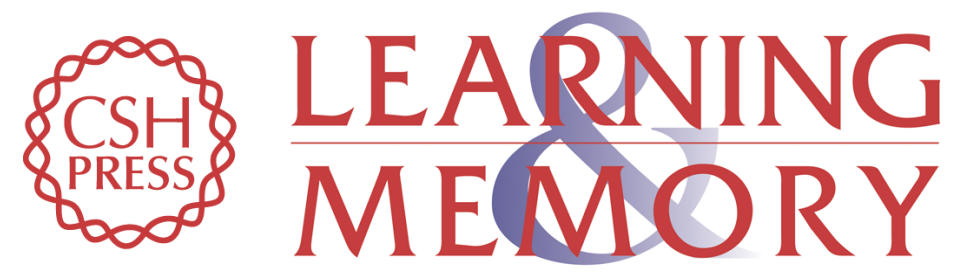

\section{The role of trait anxiety in associative learning during and after an aversive event}

Arne Ilse, Virginia Prameswari, Evelyn Kahl, et al.

Learn. Mem. 2019, 26:

Access the most recent version at doi:10.1101/Im.048595.118

\begin{aligned} & \hline References $\begin{array}{l}\text { This article cites } 26 \text { articles, } 2 \text { of which can be accessed free at: } \\ \text { http://learnmem.cshlp.org/content/26/2/56.full.html\#ref-list-1 }\end{array} \\ & \begin{aligned} \text { Creative } \\ \text { Commons } \\ \text { License }\end{aligned} \begin{array}{l}\text { This article is distributed exclusively by Cold Spring Harbor Laboratory Press for the } \\ \text { first } 12 \text { months after the full-issue publication date (see } \\ \text { http://learnmem.cshlp.org/site/misc/terms.xhtml). After } 12 \text { months, it is available under } \\ \text { a Creative Commons License (Attribution-NonCommercial } 4.0 \text { International), as } \\ \text { described at http://creativecommons.org/licenses/by-nc/4.0/. }\end{array} \\ & \begin{array}{c}\text { Receive free email alerts when new articles cite this article - sign up in the box at the } \\ \text { top right corner of the article or click here. }\end{array} \\ & \begin{array}{c}\text { Service } \\ \text { terting }\end{array}\end{aligned}$ 